J. Clin. Chem. Clin. Biocbem.

Vol. 27, 1989, pp. 87-96

(C) 1989 Walter de Gruyter \& Co.

Berlin - New York

\title{
Oxalate Measurement in the Picomol Range by Ion Chromatography: Values in Fasting Plasma and Urine of Controls and Patients with Idiopathic Calcium Urolithiasis ${ }^{1}$ )
}

\author{
By P. O. Schwille ${ }^{1}$, M. Manoharan ${ }^{1}$, G. Rümenapf ${ }^{2}, G$. Wölfel ${ }^{2}$ and H. Berens ${ }^{1}$
}

Mineral Metabolism and Endocrine Research Laboratory, Departments of Surgery ${ }^{1}$ and Urology ${ }^{2}$, University of Erlangen, FRG

(Received July 18/November 9, 1988)

Summary: Oxalate was measured by ion chromatography in the ultrafiltrate of heparinized plasma from peripheral venous blood, using a membrane with a cut-off molecular weight $\left(M_{\mathrm{r}}\right)$. The following criteria were established: sensitivity $0.7 \mu \mathrm{mol} \cdot 1^{-1}$; intra- and inter-assay coefficients of variation $4 \%$ and $12 \%$, respectively; precision of duplicate determinations (expressed as standard deviation) $0.08 \mu \mathrm{mol} \cdot 1^{-1}$; overall recovery (oxalate added and diluted, respectively) $100.7 \%$. These qualified the method for assessment of plasma oxalate in healthy human controls (males: $\mathrm{n}=12$ ) as well as patients with idiopathic renal calcium urolithiasis (males: $\mathrm{n}=22$; females: $\mathrm{n}=16$ ). Renal calcium urolithiasis patients were subclassified into those with normocalciuria and idiopathic hypercalciuria. In male and female controls the mean values (and range) of plasma oxalate were $1.98(1.4-2.5)$ and $1.78(0.7-2.9) \mu \mathrm{mol} \cdot 1^{-1}$, respectively. In male controls ultrafiltration (membrane cut off $M_{\mathrm{r}} 10000$ ) revealed that $11-16 \%$ plasma oxalate was bound to constituents having an apparent $M_{\mathrm{r}}$ above 10000 , and that with use of membranes with smaller pore size, the ultrafilterability of oxalate decreases further. In renal calcium urolithiasis the following values were elicited $\left(\mu \mathrm{mol} \cdot 1^{-1}\right)$ : male normocalciuria 1.78 $(0.8-4.0)$, idiopathic hypercalciuria $1.58(1.2-2.2)$; female normocalciuria $1.69(0.8-3.6)$, idiopathic hypercalciuria $1.21(0.8-2.1)$. The difference from controls is significant in idiopathic hypercalciuria (males and females). In contrast, in fasting urine of renal calcium urolithiasis the oxalate excretion rate $(5-45 \mu \mathrm{mol}$ per $120 \mathrm{~min}$ ) and oxalate clearance $(21-328 \mathrm{ml}$ per $\mathrm{min}$ ) resemble those in controls, whereas in renal calcium urolithiasis the fractional oxalate clearance $(30-357 \%$ of creatinine clearance) tended to higher values ( $p<0.01$, in male idiopathic hypercalciuria versus controls). - It is suggested that

1) ion chromatography allows the reliable assessment of ultrafiltrable plasma oxalate in health and disease states,

2) in renal calcium urolithiasis this technique may help to elucidate oxalate pathophysiology, especially the mode of renal handling of oxalate.

\section{Introduction}

During the past twenty-five years great efforts were made to develop accurate analyses of oxalate in biological fuids. For example, a number of methods is reported for measuring oxalate in urine (for overview see $1 . c$. $(1,2)$. This area was greatly stimulated by the progress made in research into mechanisms underly-

1) Supported by W. Sander Foundation, Munich, and in part by Deutsche Forschungsgemeinschaft, Bonn (grant Schw 210/4-2). ing recurrent idiopathic renal calcium urolithiasis in general, and by the specific role that is ascribed to oxalate in its pathophysiology. Thus, a relatively small increase in urinary oxalate is considered to drive supersaturation with calcium oxalate towards spontaneous nucleation of this stone phase (3). With the advent of ion chromatography $(4,5$; see also below), a method is now available which allows the quantitative, specific and reliable determination of oxalate in human urine $(5,6)$. 
In contrast, our knowledge of plasma oxalate and the renal handling of oxalate is still poor, because their elucidation is hampered by the lack of an easy-tomanage method for assessment of oxalate in peripheral blood. It is generally assumed that the kidney removes oxalate through the processes of glomerular filtration and additional active tubular secretion, whereas tubular oxalate reabsorption may be negligible (7). This would imply that the urinary clearance of oxalate exceeds inulin clearance. However, the postulated ratio between the two clearances of greater than unity is based on infusion of tracer oxalate and the use of a clearance formula to calculate the plasma oxalate to be $1-1.5 \mu \mathrm{mol} \cdot 1^{-1}(8)$. Data obtained with this methodology must be considered as a reference, as it is sensitive enough for detecting such low concentrations. The technique is restricted to specialized laboratories, and for ethical reasons does not allow the processing of a larger number of samples from human beings; this situation is increasingly evident, prevents direct comparison of this method with others, and forced investigators to develop independent reference methods. Given a normal mean glomerular filtration rate in $\operatorname{man}$ of $100 \mathrm{ml} \cdot \mathrm{min}^{-1}$, as measured by inulin or creatinine clearance, plasma oxalate should be around $2 \mu \mathrm{mol} \cdot 1^{-1}$ or below in order to allow for urinary oxalate clearance in the same order of magnitude, or even higher than e.g. creatinine clearance. Only recently, such low values have been reported using somewhat cumbersome chemical methods $(9,10)$.

As mentioned above the latest development in technology for measuring oxalate is ion chromatography. Several features of the technique suggested that it can be adopted not only to urine $(6,11)$ but also to deproteinized plasma, and this is confirmed in the present work. Other aims were

1) the evaluation of the method,

2) to measure plasma oxalate in controls and renal calcium urolithiasis patients of either sex,

3) to illustrate the possible mode of renal handling of oxalate by those subjects when examined under standardized conditions.

\section{Materials and Methods}

Chemicals

Analytical grade reagents and bidistilled water were used throughout. Na-carbonate, Na-bicarbonate, boric acid, sulphuric acid, oxalic acid dihydrate, and hydrochloric acid were all from Merck, Darmstadi, FRG; $\left[{ }^{14} \mathrm{C}\right]$ oxalic acid (specific activity $4.144 \mathrm{GBq} / \mathrm{mmol}$ ) was from Amersham-Buchler, Braunschweig, FRG.

\section{Equipment and principle of method}

The DIONEX 2000i ion chromatography unit (Dionex, Sunnyvale, USA) was used. The complete flow sheet of this system as applied to the measurement of urinary oxalate has been described (11). In brief: a pump, a pneumatic injection valvc with a $50 \mu \mathrm{l}$ sample loop, a guard column (HPIC AG 4A; 50 $\times 3.9 \mathrm{~mm}$ ) to protect the following anion separator column (HPIC, AS 4A; $250 \times 3.9 \mathrm{~mm}$ ) from crude particles and protein contained in unknown samples; this second and main column separates ion species from the sample according to their affinity for the resin bed; complete exchange of cations from eluants and samples is achieved by passing through a micromembrane cation exchanger, against protons from sulphuric acid $(25 \mathrm{mmol}$ $\left.\cdot 1^{-1}\right)$, thereby reducing the background conductivity of the eluant and increasing sensitivity of detection. Oxalate (and other anions) is detected by measurement of conductivity and signals recorded with an integrator (SP 4270, Spectra Physics, San José, USA).

Further equipment: Refrigerating centrifuge (J2-21, Beckman, Fullerton; USA), normal centrifuge (Rotixa, Hettich, Tuttlingen, FRG), double-tube ultrafiltration set (Centrisart I, Sartorius, Göttingen, FRG) with cellulose-tri-acetate membranes with pore sizes corresponding $M_{\mathrm{r}} 5000$ and 10000 .

\section{Chromatographic conditions}

The mobile phase containing Na-bicarbonate $\left(2 \mathrm{mmol} \cdot 1^{-1}\right.$ and Na-carbonate $\left(1.25 \mathrm{mmol} \cdot 1^{-1}\right)$ is eluted at a flow rate of $2 \mathrm{ml}$ per minute. Elution of the 25 millimolar sulphuric acid is fineregulated to $2.5 \mathrm{ml}$ per minute by use of nitrogen pressure (usually 3 psi, syn. 0.2 bar) applied to the reservoir, which flows on the other side of the membrane in the opposite direction to the eluant flow. The detector sensitivity is set at $1 \mu \mathrm{S}$, the integrator attenuation at $512 \mathrm{mV}$. Under these conditions oxalate elutes at $9.5 \mathrm{~min}$, i.e. after elution of all anions.

\section{Standard solutions}

The oxalate $\left(5 \mathrm{mmol} \cdot \mathrm{1}^{-1}\right)$ stock solution is prepared by dissolving $63 \mathrm{mg}$ oxalic acid in $100 \mathrm{ml}$ water. For measuring oxalate in the plasma ultrafiltrate (see below) of individuals with normal kidney function and tentatively normal plasma oxalate, the stock solution is diluted $1: 1000$ in water; with injection of a mixture of $35 \mu \mathrm{l}$ standard or ultrafiltrate together with $15 \mu \mathrm{l}$ boric acid $\left(0.6 \mathrm{~mol} \cdot 1^{-1}\right)$, the resulting oxalic acid concentration $\left(5 \mu \mathrm{mol} \cdot 1^{-1}\right)$ is taken as the highest calibration point; further dilutions $\left(4,3,2,1 \mu \mathrm{mol} \cdot 1^{-1}\right)$ yield a straight line passing through the zero point (see Results; fig. 1). For measurement of higher oxalate in plasma or urine (up to 0.625 $\mathrm{mmol} \cdot 1^{-1}$ ) the standards are prepared by appropriate dilutions; for urinary oxalate the sensitivity of the integrator is set at $1.024 \mathrm{~V}$.

Blood sampling, preparation of ultrafiltrate and measurement of ultrafiltrable oxalate

Fasting blood from a forearm vein was drawn into heparinized syringes, immediately transferred to pre-chilled polystyrene tubes and centrifuged at $3000 \mathrm{~g}, 4^{\circ} \mathrm{C}$, for $5 \mathrm{~min}$. Two mi plasma were instantly transferred into the outer tube of the ultrafiltration unit and, after inserting the inner tube, centrifuged at $3000 \mathrm{~g}$, under varying conditions (e. g. varying times of centrifugation) at $37^{\circ} \mathrm{C}$ and with two different types of ultrafiltration membranes (see below). In the initial period, heparinized whole blood was directly transferred to the ultrafiltration unit and processed further (see below, and Results).

The assumption of complete ultrafilterability of plasma oxalate is widely held among investigators (7). However, during the development of the present methodology a number of unex- 
pected observations were made, which necessitated expansion of the preliminary work. Among other problems, it was found that $\left[{ }^{14} \mathrm{C}\right]$ oxalic acid added to plasma is not freely filterable through the above mentioned membrane with a pore size of $M_{\mathrm{r}} 10000$, although this is commonly in use for studies of ultrafilterability at the level of renal glomeruli. In contrast, ultrafilterability appeared complete with the $M_{\mathrm{r}} 5000$ membrane within $180 \mathrm{~min}$, as verified by addition of $\left[{ }^{14} \mathrm{C}\right]$ oxalic acid (see Results; tab. 2); however, the yield of only $200 \mu l$ filtrate and less after centrifugation for $20 \mathrm{~min}$ (or for shorter periods) was too small for the analysis of oxalate. Moreover, longer centrifugation times create the risk of non-enzymatic generation of oxalate from ascorbate (see Results; tab. 2). This latter reaction has been proven (12), and in our experience there is no reliable way (including addition of inhibitors) of preventing it during ultrafiltration. Also, when ultrafiltrate was allowed to stand for 60-180 $\mathrm{min}$ at room temperature its oxalate concentration increased (see fig. 3); this was also observed in urine (13), although the oxalate increment in the latter is much smaller, compared with the total amount of oxalate present. The data from these initial studies, which were relevant to the selection of the final method for processing blood samples, are given in Results (section "oxalate in human plasma").

The following standard procedure was adopted: $2 \mathrm{ml}$ heparinized plasma from blood as mentioned above was obtained within 5-6 min, spun in the $M_{\mathrm{r}} 10000$ membrane variant of the Centrisart unit at $37 \pm \mathrm{SD} 1^{\circ} \mathrm{C}, 3000 \mathrm{~g}$, for $15 \mathrm{~min}$; the ultrafiltrate that could be harvested $(350-450 \mu \mathrm{l})$ was transferred to an Eppendorf tube, immediately frozen in liquid nitrogen and stored at $-80^{\circ} \mathrm{C}$ until analysis. For analysis, a mixture of $350 \mu \mathrm{l}$ ultrafiltrate and $150 \mu \mathrm{l}$ boric acid $(0.6 \mathrm{~mol}$ $\cdot 1^{-1}$ ) were injected into the chromatography system.

When $2 \mathrm{ml}$ heparinized whole blood is used instead of plasma, approx. $250 \mu$ l ultrafiltrate is obtained, which allows only a single determination.

Plasma oxalate and oxalate clearance in healthy controls and renal calcium urolithiasis patients

Approval for this kind of study was obtained from the local ethics committee. A total of sixty-one individuals participated in the study.

Males: controls $(n=11)$, mean age 32 years (range $20-53$ ); Renal calcium urolithiasis $(n=22)$, mean age 40 years (range 17-60);

Females: controls $(\mathrm{n}=12$ ), mean age 35 years (range $23-65$ );

Renal calcium urolithiasis $(n=16)$, mean age 38 years (range 19-62).

Further classification into the calciuria subtypes (14) were as follows: all controls were normocalciuric (calcium/creatinine ratio in fasting and postprandial urine $<0.12$ and $<0.27$, respectively); eleven male and seven female renal calcium urolithiasis patients were normocalciuric, eleven males and nine females had idiopathic hypercalciuria (fasting urinary calcium/ creatinine ratio $<0.12$ or $>0.12$, postprandial calcium/creatinine ratio $>0.27$ ).

The mean ( \pm SEM) body weight of participants was $(\mathrm{kg})$ :

Males - $74 \pm 3$ (controls), $83 \pm 3$ (normocalciuria), $85 \pm 4$ (idiopathic hypercalciuria);

Females - $60 \pm 2$ (controls), $61 \pm 4$ (normocalciuria), $64 \pm 2$ (idiopathic hypercalciuria).

All had kidney function within the normal range, as based on serum creatinine and endogenous creatinine clearance (tab. 3 ). Apart from idiopathic stone disease no other disorder was detectable at the time of the laboratory examination, and no medication was practiced ten days before or during the examination. After an overnight fast of $12-14 \mathrm{~h}$, blood (see above) and $2 \mathrm{~h}$ fasting urine were collected at 8:00 and between 8:00 and 10:00 a. m., respectively.

\section{Analyses}

Oxalate was measured in plasma by the present method, and in urine using the previously reported modification (11). Measurement of other substances followed standard laboratory procedures.

\section{Calculations and statistics}

Renal function (creatinine clearance) and the variables related to it (tab. 3) were calculated conventionally. Measured ultrafilterable oxalate was not corrected for the volume of plasma proteins or the Gibbs-Donnan factor. The data are presented in the text in the form of tables and figures. Creatinine clearance and urinary oxalate excretion rate were regressed linearly and the possibility of calculation of plasma oxalate was tested, as proposed by others (15). Total variance between controls and the two groups of renal calcium urolithiasis patients was examined by the Kruskal-Wallis test, and the significance $(p<0.05)$ of differences was examined by the U- or t-test, depending on whether Gaussian distribution was absent or present (16).

\section{Results}

Oxalate measurement at the picomol range

\section{Oxalate standards}

Figure 1A shows the linear increase of peak heights obtained with aqueous solutions containing oxalate in concentrations up to $5 \mu \mathrm{mol} \cdot 1^{-1}$. Based on the $1 \mu \mathrm{mol} \cdot 1^{-1}$ standard this corresponds to a measurement of 35 picomol per $35 \mu \mathrm{l}$ sample volume per injection (standards or unknowns). Oxalate concentration was plotted versus peak height. The regression line fitting the two is shown in figure 2; the underlying correlation coefficient (r) is 0.999 , intercept $0.88 \mathrm{mV}$ (not recognizable in fig. 2), slope 24.8.

\section{Sensitivity}

It is evident from figures 1 and 2 that the detection limit of the method is below $1 \mu \mathrm{mol} \cdot 1^{-1}$. However, sample signals below $18 \mathrm{mV}$, corresponding to 0.7 $\mu \mathrm{mol} \cdot 1^{-1}$, cannot be distinguished from the background noise of the entire instrumentation when attenuation of the integrator is set at $512 \mathrm{mV}$. It should be noted that in plasma ultrafiltrate of humans, oxalate values below $0.7 \mu \mathrm{mol} \cdot 1^{-1}$ have never been observed by us (see section „Oxalate in plasma ultrafiltrate"). 


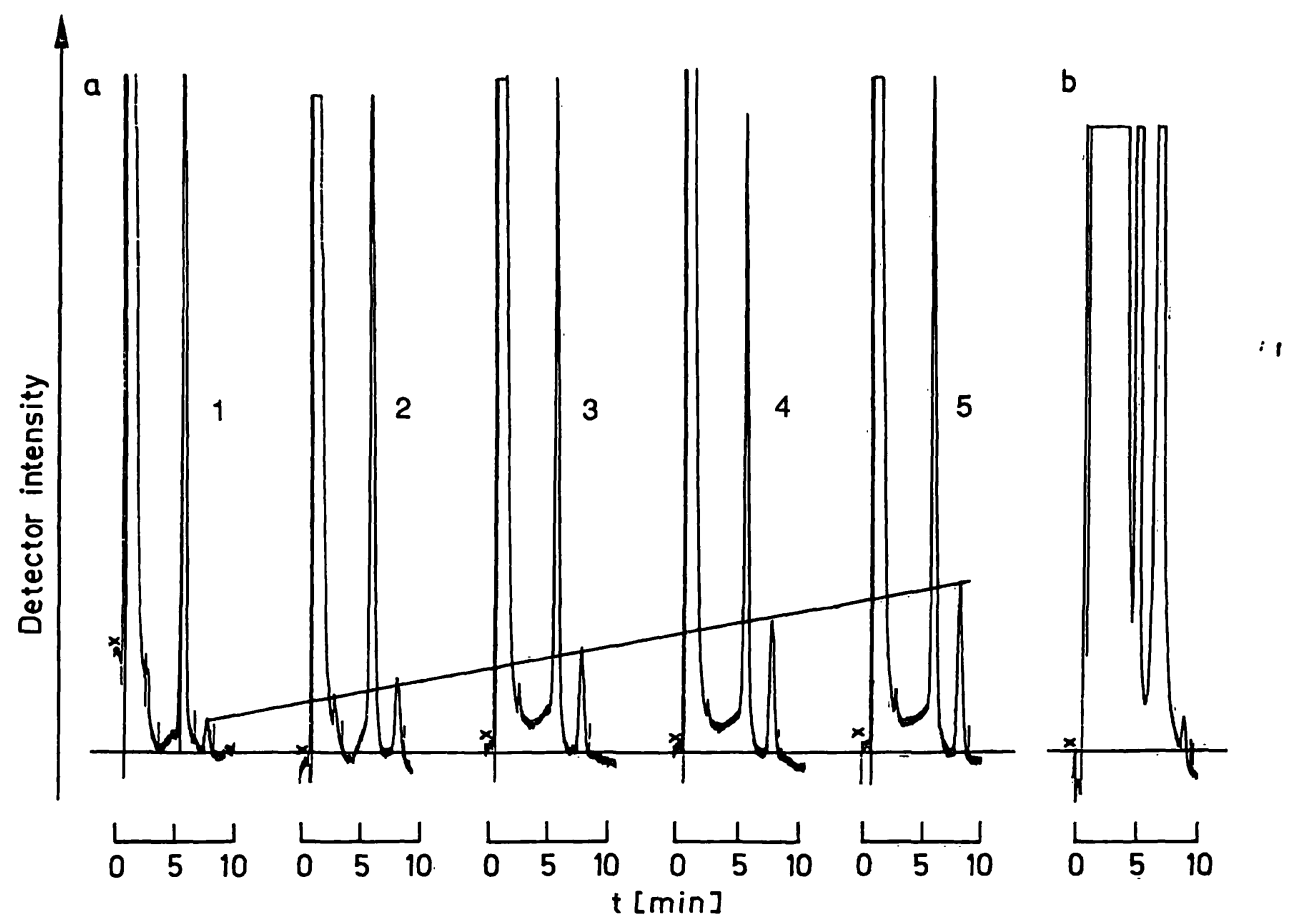

Fig. 1. Ion chromatography of oxalate. ${ }^{x}$ : denotes the position of sample injection.

a) Increasing oxalate concentration $\left(1-5 \mu \mathrm{mol} \cdot 1^{-1}\right)$ in standard solutions; for details see sections on Materials and Methods; and Results.

b) Oxalate peak in plasma ultrafiltrate of man; for further details see section on Results.

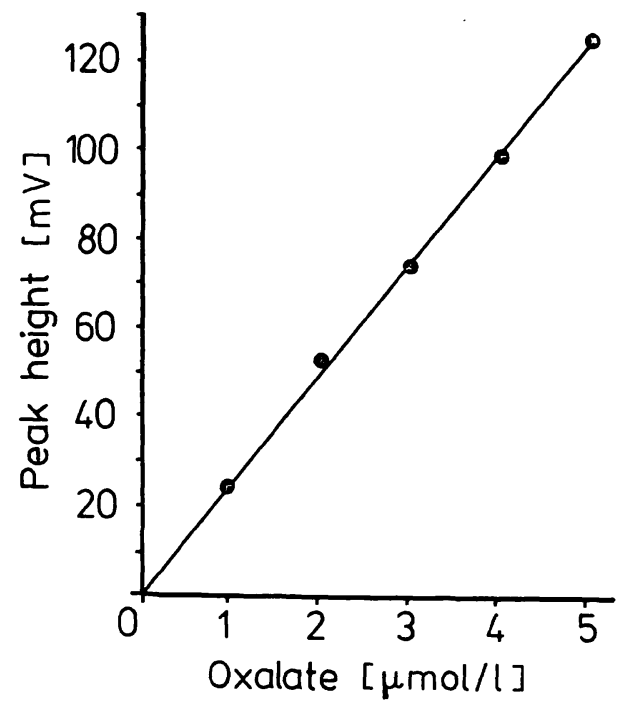

Fig. 2. Relationship between oxalate concentration and change in conductivity, expressed in millivolt (mV); $r=0.999$; for further details see section on Results.

\section{Oxalate in human plasma}

\section{Detection in plasma ultrafiltrate}

Upon injection of ultrafiltrate the oxalate peak emerges after $9.5 \mathrm{~min}$, as shown in figure $1 \mathrm{~B}$, which is identical with the one of oxalate in standard solutions; addition of standard oxalate to ultrafiltrate containing endogenous oxalate increases the peak height (see Accuracy). Potentially interfering anions in the ultrafiltrate, other than oxalate, elute earlier, for example (retention time in min): glycolate, 1.2; glyoxylate, ascorbate, creatinine all 1.5 ; sulphate, 7 ; tartrate 7.5; or later, for example urate, 20; citrate is retained on the column (data not shown). The possible non-enzymatic conversion of ascorbic acid at alkaline $\mathrm{pH}$ to oxalate during the elution process in the present work is prevented by the $15 \mu \mathrm{l}$ of $0.6 \mathrm{~mol} / \mathrm{l}$ boric acid contained in the $(50 \mu \mathrm{l})$ sample (see Methods). All these characteristics substantiate that the present method is specific for oxalate. Addition of boric acid crystals to heparinized blood in amounts representing the molarity of boric acid on the column (approx. 0.2 $\mathrm{mol} \cdot \mathrm{I}^{-1}$; see Materials and Methods, section "Standard solutions") caused no change in the concentration of ultrafilterable oxalate (data not shown). This indicates that there is no unspecific interference from ascorbate during the processing of blood samples. Addition of ascorbic acid to plasma samples in amounts within the normal range of plasma ascorbate $\left(<40 \mu \mathrm{mol} \cdot 1^{-1}\right)$ did not influence the oxalate concentration (data not shown). This finding confirms that there is no conversion of endogenous ascorbate to oxalate during the processing of plasma samples (ultrafiltration and chromatography; see Materials and Methods, section „Standard solutions”). 


\section{Precision}

The replicates $(n=10)$ of a given ultrafiltrate, when run sequentially in the same assay (intra-assay variation), resulted in a mean value ( \pm standard deviation) of $1.69(0.07) \mu \mathrm{mol} \cdot 1^{-1}$, and a coefficient of variation $(\mathrm{CV})$ of $4.05 \%$. One aliquot (from an ultrafiltrate considered as an internal laboratory control) assayed on ten separate days (inter-assay variation) gave a mean value of $0.92(0.11) \mu \mathrm{mol} \cdot 1^{-1}$, and a CV of $12 \%$. Duplicate measurement of oxalate concentration in ten unknowns (range 0.93-2.08 $\left.\mu \mathrm{mol} \cdot 1^{-1}\right)$ showed a standard deviation

$$
\left[\mathrm{SD}=\sqrt{\left(\Sigma \mathrm{d}^{2}\right) / 2 \mathrm{n}}\right]
$$

of $0.084 \mu \mathrm{mol} \cdot 1^{-1}$.

\section{Accuracy (tab. 1)}

Addition of oxalate to a given ultrafiltrate, to yield a factorial increase in the measurable oxalate concentration, results in an almost complete recovery. Di- lution with water of a given ultrafiltrate containing relatively high oxalate (obtained upon prolonged standing at room temperature) results in complete (dilution factor 2) and moderately increased (dilution factor 4) recovery, respectively. The mean overall recovery was $100.7 \%$.

\section{Degree of ultrafilterability of plasma oxalate}

As mentioned in the Methods section, major obstacles arose in identifying the conditions under which the ultrafiltrate must be prepared in order to achieve reliable oxalate measurements. A summary of the percentages of ultrafilterable $\left[{ }^{14} \mathrm{C}\right]$ oxalic acid, as obtained with membranes of either $M_{\mathrm{r}} 5000$ or 10000 pore size, various $\mathrm{pH}$ values in ultrafiltrate and the original plasma, and with increasing duration of centrifugation, is given in table 2 . It is evident that oxalate in plasma with an initial $\mathrm{pH}$ of 7.4 is freely filterable only after $180 \mathrm{~min}\left(M_{\mathrm{r}} 5000\right.$ membrane) and $60 \mathrm{~min}$ $\left(M_{\mathrm{r}} 10000\right.$ membrane) centrifugation, respectively.

Tab. 1. Accuracy of the determination of oxalate in plasma ultrafiltrate expressed as the mean ( \pm standard deviation) percentage recovery of oxalate added to, and with two dilution steps of, unknown samples.

\begin{tabular}{|c|c|c|c|c|c|}
\hline \multirow{2}{*}{$\begin{array}{l}\text { Number } \\
\text { of experiments }\end{array}$} & \multicolumn{3}{|c|}{ Oxalate $\left(\mu \mathrm{mol} \cdot 1^{-1}\right)$} & \multirow[t]{2}{*}{ Dilution } & \multirow[t]{2}{*}{ Recovery (\%) } \\
\hline & $\begin{array}{l}\text { measured } \\
\text { (mean value) }\end{array}$ & $\begin{array}{l}\text { added } \\
\text { (to individual } \\
\text { ultrafiltrates) }\end{array}$ & $\begin{array}{l}\text { recovered } \\
\text { (mean value) }\end{array}$ & & \\
\hline 6 & 1.47 & 1.43 & 1.42 & - & $99.4 \pm 8.3$ \\
\hline 6 & 1.47 & 2.86 & 2.80 & - & $98.0 \pm 8.7$ \\
\hline 6 & 1.47 & 4.30 & 4.26 & - & $99.1 \pm 4.5$ \\
\hline 3 & 4.08 & - & - & none & - \\
\hline 3 & - & - & 2.04 & $1: 2$ & $99.8+2.3$ \\
\hline 3 & - & - & 1.10 & $1: 4$ & $107.4+3.4$ \\
\hline 27 & - & - & - & - & $100.7 \pm 4.3$ \\
\hline
\end{tabular}

Tab. 2. Dependency of the ultrafilterability of plasma oxalate upon the pore size of the ultrafiltration membrane, plasma $\mathrm{pH}$, and the duration of centrifugation at $37^{\circ} \mathrm{C}$, expressed as the percentage recovery of approx. $10000 \mathrm{counts} / \mathrm{min}\left[{ }^{14} \mathrm{C}\right]$ oxalic acid from the ultrafiltrate. The $\left[{ }^{14} \mathrm{C}\right]$ oxalic acid was added to plasma after the $\mathrm{pH}$ had been adjusted to either $4.1,6.8$, 7.0 by acidification with $\mathrm{HCl}$ or left unchanged at the original value of 7.4. The concomitant oxalate concentrations, obtained with the $M_{\mathrm{r}} 5000$ membrane, are given for ultrafiltrates with $\mathrm{pH} 7.7$.

\begin{tabular}{|c|c|c|c|c|c|}
\hline \multirow[t]{2}{*}{ Duration of centrifugation (min) } & \multicolumn{4}{|c|}{$\mathrm{pH}$ of ultrafiltrate (plasma) } & \multirow{2}{*}{$\begin{array}{l}\text { Oxalate in ultrafiltrate } \\
\left(\mu \mathrm{mol} \cdot 1^{-1}\right)\end{array}$} \\
\hline & $4.5(4.1)$ & $7.2(6.8)$ & $7.4(7.0)$ & $7.7(7.4)$ & \\
\hline \multicolumn{6}{|l|}{ A. Cut-off of membrane $M_{\mathrm{r}} 5000$} \\
\hline $\begin{array}{r}20 \\
40 \\
60 \\
80 \\
120 \\
180\end{array}$ & $\begin{array}{l}27 \% \\
- \\
26 \% \\
28 \% \\
28 \% \\
33 \%\end{array}$ & $\begin{array}{l}- \\
- \\
- \\
-\end{array}$ & $\begin{array}{l}- \\
\overline{63} \% \\
66 \% \\
76 \% \\
82 \%\end{array}$ & $\begin{array}{r}58 \% \\
65 \% \\
69 \% \\
70 \% \\
84 \% \\
100 \%\end{array}$ & $\begin{array}{r}- \\
1.18 \\
1.74 \\
2.82 \\
8.05 \\
10.27\end{array}$ \\
\hline \multicolumn{6}{|l|}{ B. Cut-off of membrane $M_{\mathrm{r}} 10000$} \\
\hline $\begin{array}{l}10 \\
20 \\
30 \\
60\end{array}$ & $\begin{array}{l}- \\
- \\
-\end{array}$ & $\begin{array}{l}67 \% \\
74 \% \\
77 \% \\
90 \%\end{array}$ & $\begin{array}{l}- \\
- \\
-\end{array}$ & $\begin{array}{r}84 \% \\
89 \% \\
88 \% \\
102 \%\end{array}$ & $\begin{array}{l}- \\
- \\
-\end{array}$ \\
\hline
\end{tabular}


However, under these conditions the oxalate concentration in the ultrafiltrate is falsely elevated by a factor of 8.5 , compared with oxalate in the ultrafiltrate obtained after 40 min centrifugation $\left(M_{\mathrm{r}} 5000 \mathrm{mem}\right.$ brane; 10.27 versus $\left.1.18 \mu \mathrm{mol} \cdot 1^{-1}\right)$. This finding substantiates a considerable in vitro generation of oxalate, depending on the duration of centrifugation, and strongly suggests that the increasing ultrafilterability of $\left[{ }^{14} \mathrm{C}\right]$ oxalic acid reflects the displacement of tracer from binding sites in plasma by newly formed oxalate from other sources (see below). It should be noted that with the $M_{\mathrm{r}} 10000$ membrane, which was used in the measurement of oxalate in various groups of controls and renal calcium urolithiasis patients (tab. 3), the ultrafilterability of plasma oxalate is only $84-89 \%$ with 15 min centrifugation.

At a lower initial plasma $\mathrm{pH}$, the ultrafilterability through both types of membrane is incomplete and decreases with $\mathrm{pH}$ after either $180 \mathrm{~min}(\mathrm{pH} \mathrm{7.0,} \mathrm{5.1;}$ $M_{\mathrm{r}} 5000$ membrane) or $60 \mathrm{~min}\left(\mathrm{pH} 7.0 ; M_{\mathrm{r}} 10000\right.$ membrane) centrifugation. Also, the ultrafilterability of $\left[{ }^{14} \mathrm{C}\right]$ oxalic acid is lower at $4{ }^{\circ} \mathrm{C}$ than at $37{ }^{\circ} \mathrm{C}$ during centrifugation for $60 \mathrm{~min}$ (45 versus $79 \%$, data not shown). $\left[{ }^{14} \mathrm{C}\right]$ oxalic acid did not stick to the membranes under any of the conditions of ultrafiltration employed (data not shown). Collectively, the results show that plasma oxalate binds to some substance(s) with an apparent molecular weight above 10000 , and that measurable oxalate depends on filter pore size, $\mathrm{pH}$, and temperature.

\section{Stability of oxalate}

The results described in section „Degree of ultrafilterability ..." necessitated a more systematic study of the influence of centrifugation of plasma at $37^{\circ} \mathrm{C}$ on oxalate in the ultrafiltrate. Figure 3 a shows the oxalate pattern obtained from three healthy volunteers, indicating that during centrifugation times of up to 20 min oxalate was apparently stable, but thereafter it rose considerably within $60 \mathrm{~min}$. When the ultrafiltrate from two of these individuals was allowed to stand at $22^{\circ} \mathrm{C}$ for $60 \mathrm{~min}$ the oxalate value was relatively stable, but with prolonged standing oxalate rose again (fig. $3 \mathrm{~b}$ ). The findings point to an in vitro generation of oxalate, not only in plasma but also in its protein-free ultrafiltrate; this process is sensitive to changes in temperature, with a greater extent of oxalate generation at $37^{\circ} \mathrm{C}$ than at average room temperature.

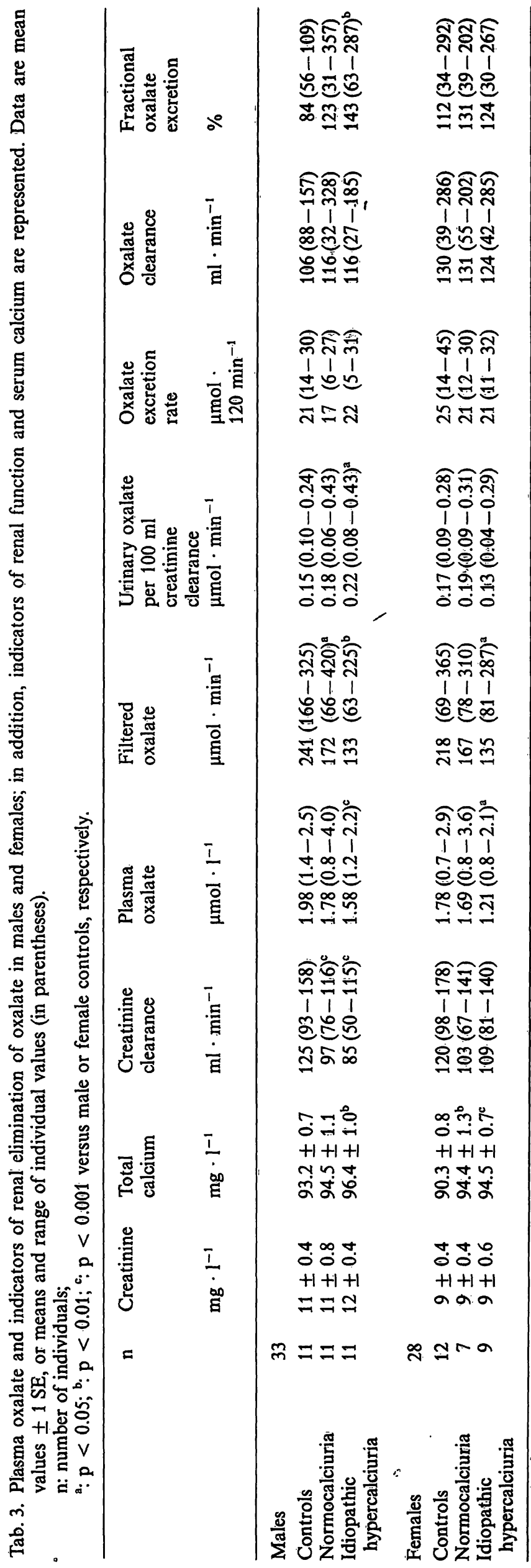

J. Clin. Chem. Clin. Biochem. ${ }^{\prime \prime} /$ Vol. 27, 1989 / No. 2 

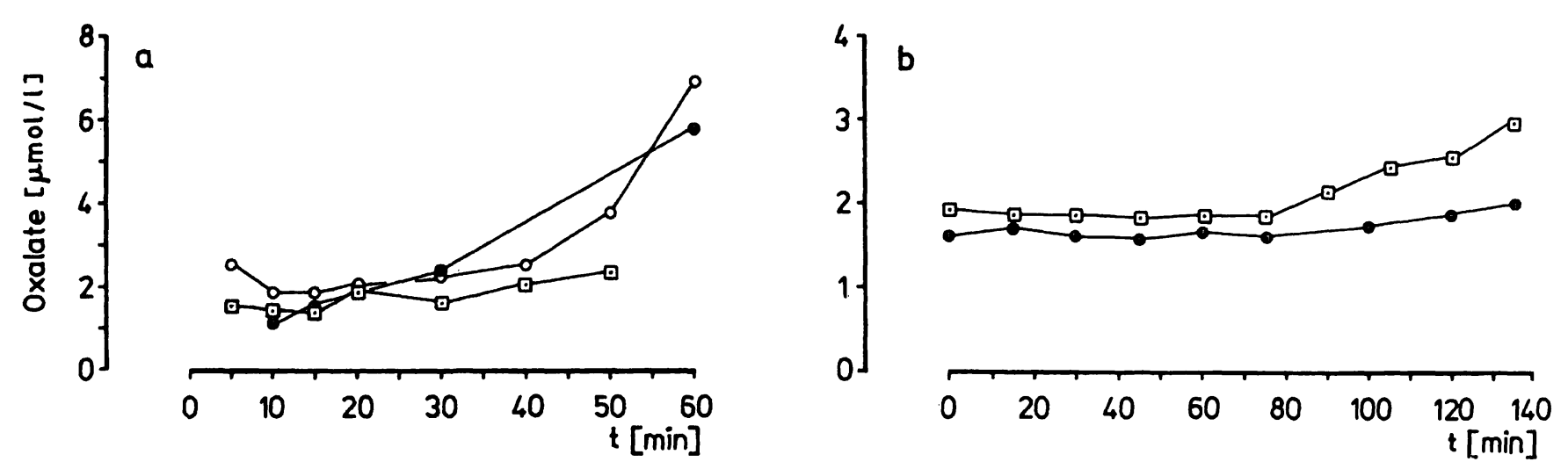

Fig. 3. Dependency of oxalate concentration in plasma ultrafiltrate upon time and temperature. Symbols denote different male individuals.

a) Effect of duration of centrifugation of plasma at $37 \pm 1^{\circ} \mathrm{C}$.

b) Effect of standing of ultrafiltrates at room temperature. Note difference in scales.

Oxalate in healthy humans and renal calcium urolithiasis patients

Oxalate in plasma ultrafiltrate (tab. 3; fig. 4)

In both controls and stone patients all mean values are $<2.0 \mu \mathrm{mol} \cdot 1^{-1}$, with a range of individual values from 0.7 (female controls) to 4.0 (male normocalciuria) $\mu \mathrm{mol} \cdot 1^{-1}$. Oxalate in renal calcium urolithiasis tends to lower values than in controls, and the difference is significant in the idiopathic hypercalciuria subgroup (males and females). As a rule, oxalate in females is lower than in males; in controls and in normocalciuria patients the mean difference is approx. 10 and $5 \%$, respectively, whereas in idiopathic hypercalciuria it is approx. $23 \%$. Figure 4 depicts more impressively the scatter of individual values, the mean values and standard deviation, and the consid- erable overlap between controls and renal calcium urolithiasis subgroups. It should be noted that the accompanying mean serum total calcium in the renal calcium urolithiasis groups is always higher than the respective values in controls (tab. 3), although all individual values are within the normal range (upper limit $105 \mathrm{mg} \cdot 1^{-1}$ in this laboratory); the difference is significant in idiopathic hypercalciuria (males), and in normocalciuria and idiopathic hypercalciuria (females).

Analysis of the ultrafiltrate from heparinized whole blood (see Methods) yielded oxalate values which are $20-30 \%$ higher than those observed in the ultrafiltrate from plasma of the same blood sample (data not shown), which is consistent with oxalate diffusion from, or rapid neoformation of oxalate inside, blood cells.

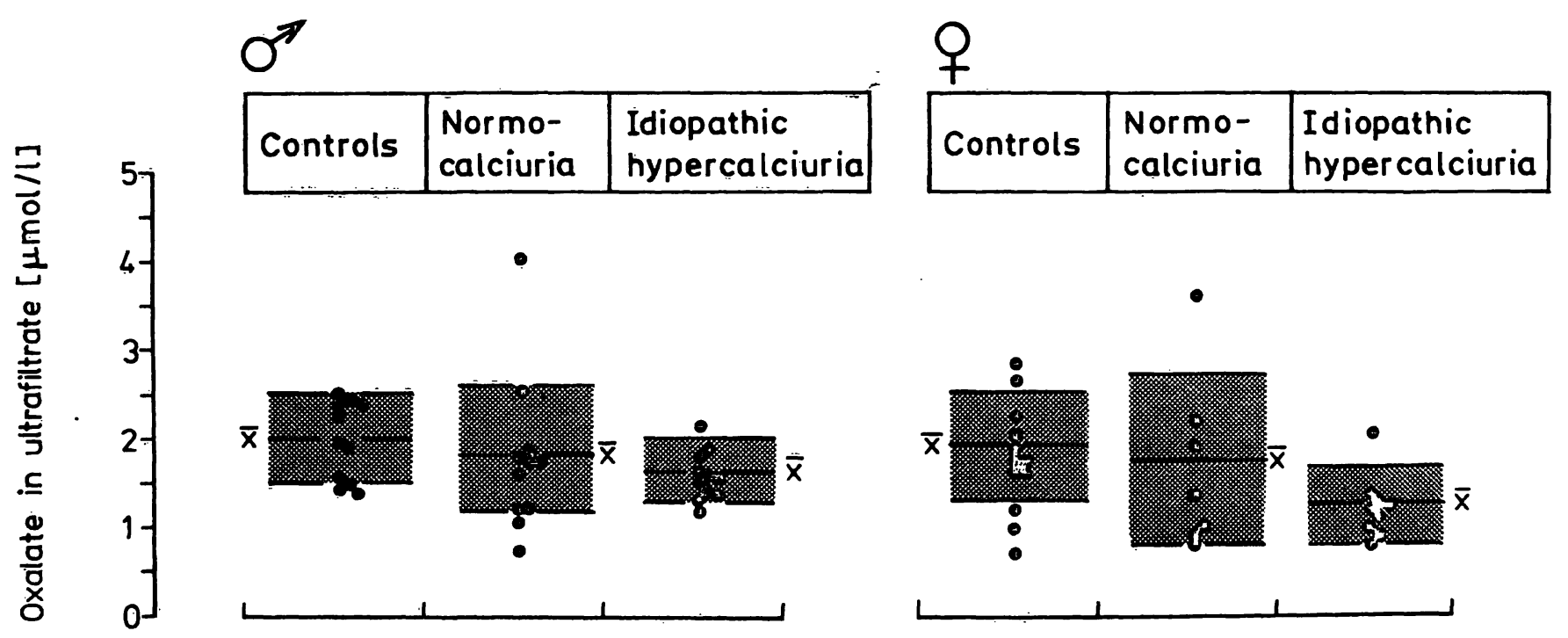

Fig. 4. Individual values for oxalate in fasting plasma ultrafiltrate of male $\left(\delta^{7}\right)$ and female (o) study participants. The hatched area comprises 1 standard deviation above and below, respectively, the mean value $(\bar{x})$. For significance of differences between groups see legend to table 3 . 
Oxalute excretion and clearance in fasting urine; renal function (tab. 3)

Owing to the lower plasma oxalate (see above) and the lower creatinine clearance in renal calcium urolithiasis, their renal handling of oxalate is characterized by a significantly decreased filtered load in three of the four groups of patients. The oxalate excretion per unit nephron, however, is unchanged, except in the male idiopathic hypercalciuria patients where it is increased. Also, the oxalate excretion rate in fasting urine is statistically unchanged in renal calcium urolithiasis (males and females) as compared with controls, and in either sex it is in the same order of magnitude. However, in renal calcium urolithiasis the mean oxalate clearance is always higher than the respective creatinine clearance and, accordingly, the fractional oxalate clearance is also higher; the latter is significantly different from controls only in the male idiopathic hypercalciuria group.

There are no significant correlations in male or female study participants between oxalate clearance and either creatinine clearance or serum creatinine.

\section{Discussion}

Our data show that by using selected techniques of sample preparation and analysis it is possible to measure reliably plasma oxalate in the picomole range in all samples studied. This contrasts with results of others, which showed that oxalate was detectable only in approx. $40 \%$ of samples (10). The micromolar concentrations $(0.7-4.0 ;$ tab. 3$)$ obtained are comparable with those obtained by using isotope clearance (8), but are lower than those employing more complex techniques (9).

\section{Oxalate assay}

Oxalate measurement with the ion chromatographic technique is simple and precise. It requires a small sample volume and no special sample preparation apart from production of ultrafiltrate. But care is necessary in the operation and calibration of the equipment. Our precision criteria for the method are consistent with its utility in daily clinical and clinical research work, for a single determination in the ultrafiltrate from $2 \mathrm{ml}$ plasma. However, smaller-scale determination $(0.5-1 \mathrm{ml}$ plasma) appears to be possible with the availability of superior devices for ultrafiltration (work in progress). Depending on the column capacity, the concentration of the eluant is altered to keep a constant oxalate retention time of approx. $10 \mathrm{~min}$, but the ratio of $\mathrm{Na}$-bicarbonate and
Na-carbonate should stay unchanged to achieve better separation of the peaks of sulphate and oxalate.

The major disadvantage of the present technique is its operational time. Plasma oxalate is measured with a detector sensitivity of $0.5 \mu \mathrm{S}$; adjustment of the system to the equilibrium status, and calibration require approx. $3 \mathrm{~h}$. We can measure about 15 samples within a normal working day. Though the oxalate peak elutes at $9.5 \mathrm{~min}$, we recommend that the next sample be injected only after $15 \mathrm{~min}$, to ensure that substances eluting after oxalate do not interfere with the subsequent oxalate peak. Other interference (electrical disturbances; gas bubbles in the suppressor column etc.) can occur and may constitute another disadvantage.

\section{Oxalate in plasma}

Clearly, the measurement of plasma oxalate necessitates adherence to a number of precautions, such as rapid work up of heparinized blood and its centrifugation at $37^{\circ} \mathrm{C}$ in a device allowing separation of watery ultrafiltrate from blood cells and proteins within $20 \mathrm{~min}$ at the most, immediate freezing of ultrafiltrates and storage at $-80^{\circ} \mathrm{C}$ until analysis. A more thorough investigation of the causes of the marked instability of oxalate, even in ultrafiltrate (fig. $3 \mathrm{~b}$ ), was beyond the scope of this study. Ascorbic acid and its oxidation product dehydroascorbic acid (17) are, however, strong candidates as oxalate precursors, even in protein-free environment. During the present work, blood samples with suggested high oxalate from patients with oxalosis and so-called enteric hyperoxaluria were not available, but the presented analytical method may be not invalidated in view of the data on oxalate recovery (tab. 1).

The apparent binding of plasma oxalate of $11-16 \%$, as demonstrated by $10-20 \mathrm{~min}$ ultrafiltration of plasma at $\mathrm{pH} 7.4$ (tab. 2), is in agreement with previous reports. Even with rather different analytical techniques [isotope dilution (18); oxalate extraction with ion exchange resin $(19,20)]$ similar fractions of binding were detected.

The nature of this binding is speculative at present but amphoteric peptides or proteins and organic cations may be considered. The presence of oxalate binding, together with improper sample preparation and the proven non-metabolic generation of oxalate [see above; (17)], may explain the higher plasma oxalate values found with other methods. When based on our values for plasma oxalate, oxalate clearance in controls is relatively low, compared with that of renal calcium urolithiasis, where it is in the range observed 
by the isotope dilution method (8); however, the latter authors argue strongly that their values may be falsely high. Thus, the decision on the "true oxalate clearance" in human health and renal calcium urolithiasis awaits direct comparison of our method with the isotope dilution method or with some yet unknown analytical procedure qualifying as reference method.

Although the physiological significance of oxalate binding is uncertain it may explain at least in part the actual measurable plasma oxalate. The molar product of calcium $\times$ oxalate is considered as an indicator of the tendency towards intravital precipitation of calcium oxalate, and based on the present oxalate values it should be lower in renal calcium urolithiasis than in controls. However, its solubility limit in aqueous solutions at thermodynamic equilibrium with the solid phase calcium oxalate monohydrate is $2.55 \times 10^{-9}$ $(\mathrm{mol} / \mathrm{l})^{2}(21)$. Therefore, the product calcium $\times$ oxalate in plasma ultrafiltrate should be far higher because of the presence of cations other than calcium that compete for oxalate ions, as well as the dependency of ion activity upon ionic strenght. On the other hand, both total and ultrafilterable plasma calcium are higher in renal calcium urolithiasis than in controls $(2,22)$, and also in this work the former is higher than normal (tab. 3). Thus, one is inclined to assume that control subjects are able to maintain a fixed calcium oxalate product by means of binding of excess oxalate to larger plasma constituents. In renal calcium urolithiasis, the stability of the product may be threatened by the rising calcium, but may be preserved by a predominance of oxalate binding to smaller-molecular plasma constituents $\left(M_{\mathrm{r}}<10000\right)$.

Clearly, there is a need to measure oxalate activity in plasma, in addition to total oxalate, and to investigate the possible oxalate binding in a variety of human disorders, as a factor contributing to the renal handling of oxalate.

\section{Oxalate in urine}

In contrast to oxalate excretion in $24 \mathrm{~h}$ urine of renal calcium urolithiasis patients, as studied in numerous laboratories, only little attention has been paid to oxalate in fasting urine. Previously, the latter was found to be normal by us (23) and others (24), but these values are probably too high, due to unspecific interference in the analytical methods then in use. Oxalate excretion in fasting urine, albeit lower than observed previously (23), is not increased numerically in renal calcium urolithiasis patients of either sex (tab. 3). It is, however, increased when relating it to the underlying low filtered load of oxalate (tab. 3; see below). Calculation of oxalate in $24 \mathrm{~h}$ urine on the basis of oxalate in fasting urine would yield levels close to those analysed in a much larger series, where they were found to be slightly but significantly higher in renal calcium urolithiasis patients than in controls (11). Thus, studies on the source of this increased oxalate in renal calcium urolithiasis should focus on whether the excess oxalate, especially in postprandial urines voided during the day, is endogenous, dietassociated, or renally mediated. For the first two possibilities there is support in the literature $(25-27)$, whereas the latter is supported by the present work. Fractional oxalate clearance in renal calcium urolithiasis above $100 \%$, especially in male idiopathic hypercalciuria (tab. 3), is consistent with net tubular oxalate secretion.

In contrast to the positive correlation found by others, between the urinary clearances of creatinine and oxalate, and a constant ratio of 2 between the clearances of oxalate and creatinine, in individuals with normal or impaired kidney function $(15,28)$, we were unable to identify any such relationship. However, the experimental protocols applied by those authors were largely different from ours, apart from their use of the $\left[{ }^{14} \mathrm{C}\right]$ oxalate isotope dilution method. We conclude that ion chromatography is useful for measuring oxalate in both plasma and urine, and that the method promiises to advance the understanding of the pathophysiology of renal calcium urolithiasis.

\section{Acknowledgement}

We are grateful to $I$. Goldberg for secretarial assistance.

\section{References}

1. Larsson, L. \& Tiselius, H. G. (1987) Min. Electr. Metab. $13,242-250$.

2. Schwille, P. O. \& Rümenapf, G. (1988) In: Renal Tract Stone; Metabolic Basis and Clinical Practice (Wickham, I. E. A. \& Buck, A. C., eds.) in press, Churchill Livingstone, London.

3. Robertson, W. G., Peacock, M. \& Nordin, B. E. C. (1972) In: Urolithiasis: Physical Aspects (Finlayson, B., Hench, L. L. \& Smith, L. H., eds.) pp. 79-95, National Academy of Sciences, Washington.

4. Menon, M. \& Mahle, J. C. (1983) Clin. Chem. 29, 269371.

5. Robertson, W. G. \& Scurr, S. (1984) Clin. Chim. Acta 140. 97-99.

6. Manoharan, M., Sörgel, F., Schwille, P. O., Hofmann, H. \& Sigel, A. (1985) Fortschr. Urol. Nephrol. 23, 222-229.

7. Greger, R. (1981) In: Renal Transport of Organic Substances (Greger, R., Lang, F. \& Silbernagl. S., eds.) pp. 224-233, Springer, Berlin, Heidelberg, New York. 
8. Hodgkinson, A. \& Wilkinson, R. (1974) Clin. Sci. Molec. Med. 46, 61-73.

9. Kasidas, G. P. \& Rose, G. A. (1986) Clin. Chim. Acta 154, $49-58$.

10. Parkinson, J. S., Kealey, T. \& Laker, M. F. (1986) Clin. Chim. Acta 152, 335-345.

11. Manoharan, M., Schwille, P. O., Rümenapf, G., Berger, I., Meister, R., Wölfel, G. \& Berens, H. (1988) Urol. Res. 16, 190 (abstract).

12. Herbert, A. W., Hirst, E. L., Percival, E. G. W. (1933) J. Chem. Soc. $1270-1290$.

13. Mahr, G., Sörgel, F. \& Schwille, P. O. (1986) Fortschr. Urol. Nephrol. 25, 158-162.

14. Scholz, D. \& Schwille, P. O. (1981) Dtsch. Med. Wochenschr. 106, 99-102.

15. Prenen, I. A. C., Doorhout Mees, E. J. \& Boer, P. (1985) Europ. J. Clin. Invest. 15, 45-49.

16. Campbell, R. C. (1971) Statistische Methoden für Biologie und Medizin, Thieme, Stuttgart.

17. Hughes, C., Dutton, S. \& Stewart Truswell, A. (1981) J. Hum. Nutr. 35, 274-280.

18. Constable, A. R., Joekes, A. M., Kasidas, G. P., O'Regan, P. \& Rose, G. A. (1979) Clin. Sci. 56, $299=304$.
19. Krügers-Dagneaux, P. G. L. C., Klein Elhorst, J. T. \& Olthuis, F. M. F. G. (1976) Clin. Chim. Acta 71, 319-325.

20. Chambers, M. M. \& Russell, J. C. (1973) Clin. Biochem. $6,22-28$.

21. Finlayson, B. (1977) In: Calcium Metabolism in Renal Failure and Nephrolithiasis (David, D. S., ed.) pp. 337382, John Wiley \& Sons, New York.

22. Schwille, P. O., Rümenapf, G., Köhler, R. \& Schmidtler, J. (1987) Clin. Exp. Endocrinol. 90, 71-75.

23. Schwille, P. O., Paulus, M., Scholz, D. i\& Sigel, A. (1978) Urologe A 17, 217-219.

24. Hodgkinson, A. (1978) Clin. Sci. Molec. Med. 54, $291-$ 294.

25. Kasidas, G. P. \& Rose, G. A. (1987) Fortschr. Ürol. Nephrol. 26, 226-229.

26. Erickson, S. B., Cooper, K., Broadus, A. E., Smith, L. H., Werness, P. G., Binder, H. J. \& Dobbins, J. W. (1984) Clin. Sci. 67, 131-138.

27. Schwille, P. O., Hanisch, E. \& Scholz, D. (1984) J. Urol. $132,650-655$.

28. Prenen, J. A. C., Boer, P., Dorhout Mees, E. J., Endeman, H. J., Spoor, S. M. \& Oei, H. Y. (1982) Clin. Sci. 63, $47-51$.

Prof. Dr. Dr. P. O. Schwille

Universitäts-Krankenhaus

Chirurgische Klinik

Maximiliansplatz 2

D-8520 Erlangen 